Journal of Biotechnology and Strategic Health Research

Derleme / Review

http://dergipark.org.tr/tr/pub/bshr

\title{
COVID-19 Salgınında Sağlık Çalışanlarında Risk Azaltılması
}

\author{
Risk Reduction in Healthcare Workers in the COVID-19 Outbreak
}

(D) $\triangle$ Sultan Pınar Çetintepe ${ }^{1}$, (D) Mustafa Necmi İlhan²

${ }^{1}$ İş ve Meslek Hastalıkları, Derince Eğitim ve Araştırma Hastanesi, Kocaeli.

${ }^{2}$ Halk Sağlığı Anabilim Dalı, Gazi Üniversitesi Tip Fakültesi, Ankara

ORCID ID: Sultan Pınar Çetintepe 0000-0001-5434-8895, Mustafa Necmi İlhan 0000-0003-1367-6328

^Sorumlu Yazar / Corresponding Author: Dr. Sultan Pınar Çetintepe, e-posta / e-mail: spinarcetintepe@gmail.com

Geliş Tarihi / Received : 01.04.2020 Kabul Tarihi / Accepted: 09.04.2020 Yayın Tarihi / Online Published: 10.04.2020

Atıf Gösterimi/How to Cite: Çetintepe S.P., İlhan M.N., COVID-19 Salgınında Sağlık Çalışanlarında Risk Azaltılması, J Biotechnol and Strategic Health Res. 2020;1(Özel Sayı):50-54

Öz

Aralık 2019'dan beri görülmeye başlayan COVİD-19 salgını tüm dünyayı etkilemiştir. 11 Mart 2020'de ülkemizde ilk vaka tespit edilmiştir. Yoğun infektivitesi olan bu virüs karşısında sağlık çalışanları en yüksek risk altındaki meslek grubudur. Çin’de salgın sırasında ilk üç ay içinde 1500’ün üzerinde sağlık çalışanı enfekte olmuştur. Bu yüksek maruziyet riski nedeniyle gözlük, bone, tulum, maske gibi kişisel koruyucu donanımların yerinde ve uygun kullanımı önem kazanmaktadır. Bu derlemede sağlık çalışanlarının COVİD-19 salgınında iş sağlığı ve güvenliği ilkeleri kullanılarak mesleki bulaş risklerini azaltma yolları ve yöntemleri irdelenmiştir.

Anahtar iş sağlığı, sağlık çalışanı, kişisel koruyucu donanım, COVID-19

Kelimeler

Abstract

The epidemic of COVID-19, which started to appear since December 2019, has affected the world. The first case was detected in our country on March 11, 2020. Healthcare professionals are the highest-risk occupational groups against this virus. During the epidemic in China, more than 1,500 health workers were infected in the first three months. Due to this high risk of exposure, proper use of personal protective equipment such as goggles, bones, protective clothes and masks becomes important. In this review, methods of reducing occupational transmission risks of healthcare workers were evaluated by using occupational health and safety principles in COVID-19 outbreak.

Keywords occupational health, healthcare workers, personel protective equipment, COVID-19 


\section{GIIRIŞ}

Çin Halk Cumhuriyeti (PRC) Hubei Eyaleti Wuhan'da Aralık 2019'un sonlarında tanımlanamayan bir pnömoni vakası bildirilmiştir. Klinik özellikleri viral pnömoniye çok benzer olduğu vurgulanmıştır. Solunum örnekleri üzerinde yapılan analizlerden sonra, Çin Halk Cumhuriyeti Hastalık Kontrol Merkezleri uzmanları, daha sonra yeni koronavirüs pnömonisi (NCP) olarak bilinen pnömoniye yeni koronavirüsün neden olduğunu açıklamıştır ${ }^{1}$. Dünya Sağlık Örgütü hastalığı resmen COVID-19 olarak adlandırmıştır. Uluslararası Virüs Taksonomisi Komitesi (ICTV), virüsü şiddetli akut solunum sendromu koronavirüs 2 (SARS-CoV-2) olarak adlandırmıştır. Yeni koronavirüs ve neden olduğu hastalık için resmi bir adın belirlenmesi, klinik ve bilimsel araştırmalarda ortak dil kullanılması açısından uygun bir yaklaşımdır².

SARS ve MERS ile karşılaştırıldığında, bu virüs düşük mortalite oranına rağmen yüksek bulaşıcılık ve enfektiviteye sahiptir ${ }^{3}$. Yeni koronavirüs dizilerinin genom analizi, SARS-CoV ve yarasa SARS koronavirüsünün (SARSr-CoV-RaTG13) tam genom dizisi tanıma oranlarının sırasıyla $\% 79,5$ ve $\% 96$ olduğunu ortaya koymuştur ${ }^{4}$. Bu durum koronavirüsün yarasa kaynaklı olabileceği anlamına gelebilir. 29 Şubat 2020'de Dünya Sağlık Örgütü tarafından yayınlanan veriler, ilk vakanın rapor edildiği 12 Aralık 2019'dan bu yana 79.394 vakanın yeni koronavirüs ile enfekte olduğunu doğruladı ve toplam 2.838 kişinin öldüğünü göstermiştir ${ }^{5}$. Ülkemizde de 11 Mart'ta ilk koronavirüs vakası açıklanmıştır. DSÖ'nün güncel verilerine göre dünya genelinde vaka sayısı 416,686 olarak saptanmışken ölüm sayısı 18,589'dur' ${ }^{6} 197$ ülkede vaka görülmesi üzerine hastalık DSÖ tarafından pandemiolarak ilan edilmiştir.

Mevcut Korona Virüsü Hastalığı (COVID-19) salgını göz önüne alındığında, Wuhan'da ilk 15 etkilenen vaka bildirildiğinden beri sağlık personeli arasındaki enfeksiyonun yaygın olduğu saptanmıştır ${ }^{7} .11$ Şubat 2020'ye kadar toplam 1716 Çinli sağlık çalışanının COVID-19 tarafından enfekte olduğu tahmin edilmiştir ${ }^{8}$.
Bu derlemede sağlık çalışanlarının COVİD-19 salgınında iş sağlı̆̆ı ve güvenliği ilkeleri kullanılarak mesleki bulaş risklerini azaltma yolları ve yöntemlerinin irdelenmesi öngörülmüştür.

\section{Virüsün Genel Özellikleri}

Koronavirüsler, bölümlenmemiş tek zincirli pozitif zincirli RNA virüsleridir. Koronavirüsler, Coronaviridae ailesinin Coronavirus cinsine aittir. Virüsün zarfındaki çelenk şeklindeki çıkıntılardan adlandırılır.

Virüsler genellikle pürüzsüz yüzeylerde birkaç saat hayatta kalabilirler. Sıcaklık ve nem izin verirse, birkaç gün hayatta kalabilirler. Yeni koronavirüs ultraviyole ışınlarına ve ısıya duyarlıdır. $132.8^{\circ} \mathrm{F} 30$ dakika boyunca sürekli 1sı, eter, $\% 75$ alkol, klor içeren dezenfektanlar, perasetik asit, kloroform ve diğer lipit çözücüler virüsü etkili bir şekilde etkisiz hale getirebilir. Klorheksidin (klorheksidin glukonat) de virüsü etkin bir şekilde etkisiz hale getirir?.

$\mathrm{Bu}$ virüsler esas olarak damlacıklar yoluyla bulaşır ve fekal-oral yoldan da yayılabilir. Korona virüsü enfeksiyonu insidansı kış ve ilkbaharda yaygındır. Virüsün kuluçka süresi 1 ila 14 gün arasındadır ${ }^{9}$.

Dayanıklılık çalışmasında SARS-CoV-2, plastik ve paslanmaz çelik yüzey üzerinde bakır ve kartondan daha kararlı olup ve bu virüslere uygulandıktan sonra 72 saate kadar canlı virüs tespit edilmiştir ${ }^{10}$.

\section{Klinik Özellikler}

SARS-CoV-2 enfeksiyonunun en sık görülen klinik semptomları ateş (\% 87.9), öksürük (\% 67.7), yorgunluk (\% 38.1) iken ishal (\% 3.7) ve kusma (\% 5.0) daha seyrek görülen semptomlardandır ${ }^{11}$. Çoğu hastada başvuru sırasında bir dereceye kadar dispne olabilir. Semptomların başlangıcından akut solunum sıkıntısı sendromunun (ARDS) gelişimine kadar geçen süre COVID-19 enfeksiyonu olan ilk hastalar arasında sadece 9 gün olarak saptanmıştır ${ }^{1}$. Ayrıca, ciddi hastalar akut solunum sıkıntısı sendromu, 
akut kalp hasarı ve ikincil enfeksiyon dahil olmak üzere çeşitli komplikasyonlara eğilimlidir. Genel olarak, koronavirüsün radyografik özellikleri, diğer organizmaların neden olduğu toplum kökenli pnömonide bulunanlara benzemektedir ${ }^{12}$. Akciğer bilgisayar tomografisi taraması bu pnömoniyi teşhis etmek için önemli bir araçtır. Yeni bir çalışmada, çoğu hastada (\% 90) bilateral göğüs BT bulguları olduğu ve göğüs BT’sinin COVID-19 tanı duyarlılı̆̆1nın \% 97 olduğu bildirilmiştir ${ }^{13}$.

Laboratuvar incelemesinde hastaların\% 82.1'inin lenfopeni ve\% 36.2'sinin trombositopeni olduğu ortaya çımıştır. Ek olarak, çoğu hastada yüksek seviyelerde C-reaktif protein, laktat dehidrojenaz ( $\mathrm{LDH} \bigotimes$ ve kreatinin kinaz $₫ \mathrm{CK} \bigotimes$ görülmüştür. Hastaların bazılarında da yüksek transaminaz, anormal miyokardiyal enzim spektrumu veya yüksek serum kreatinin saptanmıştır ${ }^{11}$.

\section{Sağlık Çalıșanı Risk Sınıflandırması}

Solunum sekresyonları dışındaki vücut sıvıları COVID-19'un bulaşmasında açık bir şekilde ilişkilendirilmemiş olsa da, kan, dışkı, kusma ve idrar gibi diğer vücut sıvılarıyla korunmasız temas sağlık çalışanını COVID-19 riskine sokabilir.

Yüksek riskli Maruz Kalım: Yüz maskesi takmayan COVID-19 hastaları ile uzun süre yakın temasta bulunan ve burun-ağız bölgesi enfekte materyale maruz kalan sağlık çalışanını ifade eder.

Aerosol üreten prosedürler esnasinda veya COVID-19 hastalarında solunum salgılarının kontrol edilemediği durumlarda (örn., Kardiyopulmoner resüsitasyon, entübasyon, ekstübasyon, bronkoskopi, nebulizatör tedavisi, balgam indüksiyonu) gözler, burun veya ağzını korumayan sağlık çalışanı ayrıca yüksek riskli olarak kabul edilir. Orta Riskli Maruz Kalım: Yüz maskesi takan COVID-19 hastaları ile uzun süre yakın temasta bulunan ve burun-ağız bölgesi enfekte materyale maruz kalan sağlık çalışanını ifade eder. Aerosol üretici bir prosedür sırasında bir elbise, eldiven, göz koruması ve bir maske (filtreli maske yerine) giyen sağlık çalışanının orta riskli bir maruz kaldığı düşünülecektir.

Düşük riskli maruz Kalım: Genel olarak COVID-19 hastaları ile kısa etkileşimleri tanımlar. Sağlık çalışanının bir yüz maskesi veya filtreli maske takarken kaynak kontrolü için yüz maskesi giyen hastalarla uzun süreli yakın temas anlamına gelir. Bir yüz maskesi veya solunum cihazına ek olarak göz korumasının kullanılması maruz kalma riskini daha da azaltacaktır.

CDC kılavuzuna göre maskesiz COVID-19 hastası ile uzamış maruz kalımı olan sağlık çalışanı herhangi bir kişisel koruyucu donanım (KKD) kullanmamışsa ve yüksek riskli maruz kalım ise 14 gün ișten uzaklaştırılmalıdır. Maskesiz COVID-19 hastası ile uzamış maruz kalımı olan sağlık çalışanı göz koruması kulanmamış ve orta riskli maruz kalım varsa 14 gün işten uzaklaştırılmalıdır. Maske takmış olan COVID-19 hastasıyla KKD’siz olarak uzamış maruz kalan sağlık personeli ve orta riskli maruz kalım varsa 14 gün ișten uzaklaştırılmalıdır ${ }^{14}$.

\section{Sağlık Çalışanlarını Korumak için Ne Yapmalı ${ }^{15}$ Mühendislik Önlemleri}

- Sağlık tesislerinde uygun klima santrallerinin kurulduğundan ve bakımının yapıldığından emin olun.

- CDC bilinen veya șüphelenilen COVID-19 hastalar1nın bir enfeksiyon izolasyon odasına yerleștirilmesini önerir.

- Bilinen veya șüphelenilen COVID-19 hastalarında aerosol üreten prosedürler gerçekleştirmek için izolasyon odaları kullanın.

- Postmortem çalışmalarda ölümleri sırasında COVID-19’a sahip olduğu veya sahip olduğundan şüphelenilen kişilerin vücutları üzerinde aerosol üretici prosedürler uygularken özel otopsi odası veya diğer benzer izolasyon tesislerini kullanın.

- Bilinen veya şüphelenilen COVID-19 hastalarından alınan numuneleri tutarken Biyogüvenlik Seviye 3 ile 
ilişkili özel önlemler alın.

\section{İdari Önlemler}

- Tek kişilik odaların bulunmadığı durumlarda COVID-19 hastalarını gruplama gibi maruziyeti azaltan politikalar geliştirmek ve uygulamak.

- Hastalardan ve aile üyelerinden, sağlik kuruluşuna vardıklarında solunum yolu rahatsızlığı belirtilerini derhal bildirmelerini ve tek kullanımlık yüz maskeleri kullanmasını isteyen posterler yapıştırın.

- COVID-19 salgınları sırasında çalışanların gelişmiş tıbbi takibini sunmayı önerin.

- Tüm çalışanlara başlangıç ve yenilenme eğitimi de dahil olmak üzere COVID-19'un bulaşmasını önleme konusunda işe özgü eğitim ve öğretim sağlayın.

- Çalışanların stresine yönelik psikolojik ve davranışsal desteğin mevcut olduğundan emin olun.

\section{Güvenli Çalışma Ortamı}

- Sahada dekontaminasyon için en az \% 60 alkol içeren alkol bazlı el losyonlarını acil müdahale ekiplerine ve maruz kalabilecek diğer önemli personele verin.

\section{Kişisel Koruyucu Donanım}

Yüksek veya çok yüksek maruz kalma riskine sahip sağlık çalışanlarının iş görevlerine ve maruz kalma risklerine bağlı olarak eldiven, önlük, yüz siperi, gözlük ve bir yüz maskesi veya solunum maskesi takması gerekir.

Türkiye’de Halk Sağlığı Genel Müdürlüğü tarafından önerilen Kişisel Koruyucu Donanım tablosu aşağıda özetlenmiștir ${ }^{16}$.

\begin{tabular}{|c|c|c|c|}
\hline \multicolumn{4}{|c|}{ YATAKLI TEDAVİ KURUMLARI } \\
\hline Yer & Hedef personel & Aktivite & KKD \\
\hline \multirow[t]{3}{*}{ Hasta Odası } & Sağlık Personeli & Hastaya direk bakım verme & $\begin{array}{c}\text { Tibbi maske (Cerrahi maske) Önlük, Eldiven, } \\
\text { Gözlük/Yüz koruyucu }\end{array}$ \\
\hline & & $\begin{array}{c}\text { Damlacık çekirdeği: aerosol oluş- } \\
\text { turan işlemler }\end{array}$ & $\begin{array}{c}\text { N95 ya da FFP2 ya da eşdeğeri maske, Eldiven, } \\
\text { Gözlük/Yüz koruyucu, Önlük }\end{array}$ \\
\hline & Temizlik personeli & Hasta odasına girerken & Tibbi maske, Önlük, Eldiven \\
\hline Triyaj & Sağlık personeli & $\begin{array}{l}\text { Hastayla doğrudan temas içermey- } \\
\text { en ön değerlendirme }\end{array}$ & $\begin{array}{c}\text { En az } 1 \text { metre mesafeyi sağlayacak şekilde } \\
\text { yapılmalıdır. Kişisel koruyucu ekipmana gerek } \\
\text { yoktur.(1 metre mesafe korunamayacaksa tıbbi } \\
\text { maske takılmalıdır) }\end{array}$ \\
\hline Laboratuvar & Laboratuvar teknisyeni & Solunum örnekleri çalışılırken & $\begin{array}{l}\text { Tibbi maske, Önlük, Eldiven Gözlük / Yüz } \\
\text { koruyucu (sıçrama riski varsa) }\end{array}$ \\
\hline Ofis alanları & $\begin{array}{l}\text { Sağllk personeli dahil tüm } \\
\text { personel }\end{array}$ & $\begin{array}{l}\text { Hastalarla temas gerektirmeyen } \\
\text { tümidari görevler }\end{array}$ & Kişisel koruyucu ekipmana gerek yoktur. \\
\hline \multirow[t]{2}{*}{ Poliklinik } & Sağlık personeli & $\begin{array}{l}\text { Solunum yolu semptomları olan } \\
\text { hastanın muayenesi sirasında }\end{array}$ & $\begin{array}{c}\text { Tibbi maske, Önlük, Eldiven Gözlük/Yüz } \\
\text { koruyucu }\end{array}$ \\
\hline & Sağlık personeli & $\begin{array}{l}\text { Solunum yolu semptomları olma- } \\
\text { yan hastaların muayenesi sirasında }\end{array}$ & $\begin{array}{l}\text { Standart önlemler ve risk değerlendirmesine } \\
\text { göre KKD }\end{array}$ \\
\hline
\end{tabular}

Sonuç olarak COVİD-19 enfeksiyonu sağlık çalışanları için mesleki risk oluşturmaktadır. Sağlık Bakanlığının ve Türkiye Halk Sağlığı Gnele Müdürlüğü’nün rehberleri ön- derliğinde ve literatürle uyumlu kişisel koruyucu donanım kullanılması enfeksiyonun sağlık çalışanlarına bulaş riskini azaltmaktadır. 
J Biotechnol and Strategic Health Res. 2020;1(Özel Sayı):50-54

ÇETINTEPE, İLHAN, COVID-19 Salgını ve Sağlık Çalışanları

\section{Kaynaklar}

1. Huang C, Wang Y, Li X, et al. Clinical features of patients infected with 2019 novel coronavirus in Wuhan, China. Lancet. 2020;395(10223):497-506.

2. Wang LS, Wang YR, Ye DW, Liu QQ. A review of the 2019 Novel Coronavirus (COVID-19) based on current evidence. Int J Antimicrob Agents. 2020:105948.

3. Liu Y GA, Wilder-Smith A, Rocklov J. . The reproductive number of COVID-19 is higher compared to SARS coronavirus. J Travel Med 2020.

4. Chen N, Zhou M, Dong X, et al. Epidemiological and clinical characteristics of $99 \mathrm{ca}$ ses of 2019 novel coronavirus pneumonia in Wuhan, China: a descriptive study. Lancet. 2020;395(10223):507-513.

5. WHO. Coronavirus disease 2019(COVID-19) Situation. 2020

6. WHO. Novel Coronavirus (COVID 19) Situaiton. https://experiencearcgiscom/experience/ 685d0ace521648f8a5beeeee1b9125cd. 26-03-2020.

7. 15 medical staff are diagnosed as COVID-19 in Wuhan. . Xinhua Net 1-02-2020; http:// www.xinhuanet.com/local/2020-01/21/c_1125487270.htm.

8. News. TB. A total of 1716 Chinese HCWs were infected by COVID-19 till February 11, 2020. . Available at: http://wwwbjnewscomcn/news/2020/02/14/689319html 2-03-2020.

9. Zou W. The Coronavirus prevention handbook Wuhan, China: Hubei Science and Technology Press; 2020.
10. Neeltje van Doremalen TB. Aerosol and Surface Stability of SARS-CoV-2 as Compared with SARS-CoV-1. NEJM. 17-03-2020.

11. Guan W-j NZ-y, Hu Y, Liang W-h, Ou C-q, He J-x, et al. Clinical characteristics of 2019 novel coronavirus infection in China. NEJM. 2020

12. Wong KT, Antonio GE, Hui DS, et al. Severe acute respiratory syndrome: radiographic appearances and pattern of progression in 138 patients. Radiology. 2003;228(2):401-406.

13. Ai T, Yang Z, Hou H, et al. Correlation of Chest CT and RT-PCR Testing in Coronavirus Disease 2019 (COVID-19) in China: A Report of 1014 Cases. Radiology. 2020:200642.

14. CDC. Interim U.S. Guidance for Risk Assessment and Public Health Management of Health care Personnel with Potential Exposure in a Healthcare Setting to Patients with Coronavirus Disease (COVID-19) wwwcdcgov , guidance-risk-assesment-hcp. 07-03-2020.

15. OSHA. Guidance on Preparing Workplaces for COVID-19. wwwoshagov , Publications , OSHA3990. 03-2020.

16. müdürlü̆̈̈ THSg. COVID-19 HASTALIĞINA YÖNELIK SAĞLIK KURULUȘU, PERSONEL VE FAALIYET TÜRÜNE GÖRE KULLANILMASI ÖNERILEN KORUYUCU EKIPP MANLAR. covid19 rehberler. 03-2020; https://hsgm.saglik.gov.tr/tr/depo/covid19/rehber ler/COVID_TABLE_HSGM.pdf?type=file. 